\title{
Disrupting Circadian Rhythms in Rats Induces Retrograde Amnesia
}

\author{
MÁTYÁS FEKETE, ${ }^{1}$ JAN M. VAN REE, ${ }^{2}$ RAYMOND J. M. NIESINK \\ AND DAVID DE WIED \\ Rudolf Magnus Institute for Pharmacology, Medical Faculty, University of Utrecht, Vondellaan 6 \\ 3521 GD Utrecht, The Netherlands
}

Received 20 September 1984

\begin{abstract}
FEKETE, M., J. M. VAN REE, R. J. M. NIESINK AND D. DE WIED. Disrupting circadian rhythms in rats induces retrograde amnesia. PHYSIOL BEHAV 34(6) 883-887, 1985.-Disrupting circadian organization in rats by phase-shifting the illumination cycle or by exposure to a reversed day/night cycle or to continuous light, resulted in retrograde amnesia for passive avoidance behavior. This retrograde amnesia induced by phase-shifting lasted at least 2 days, and gradually diminished the longer the rats were exposed to the new illumination cycle. Retention performance was not impaired when rats were exposed to phase-shifting for 3-5 days before the learning trial. The retrograde amnesia due to changing the illumination cycle is probably due to retrieval disturbances. Extinction of active avoidance behavior was facilitated in rats exposed to a phase-shifted illuminiation cycle, but social and explorative behavior of rats tested in dyadic encounters were not affected by changing the normal illumination cycle. It is concluded that phase-shifting may result in amnesia for newly learned behavioral responses, but not for more innate behavioral patterns.
\end{abstract}

$\begin{array}{llll}\text { Circadian organization } & \text { Retrograde amnesia } & \text { Active avoidance behavior } & \text { Day/night cycle } \\ \text { Passive avoidance behavior } & \text { Social behavior } & \end{array}$

CIRCADIAN organization may play a critical role in memory processes $[4,5,9,10]$. Thus phase-shifting circadian rhythms in rats shortly after passive avoidance training impaired their performance during retention testing, suggesting that disrupting circadian organization produces retrograde amnesia [9]. In the present experiments we used the passive avoidance test procedure to analyse memory processes of rats, and disturbed circadian organization of the animals by changing the usual light/dark illumination schedule. The studies were designed, (1) to compare the effects of phaseshifting the light/dark cycle with those of constant exposure to light and of a reversed day/night cycle, (2) to analyse the duration of the amnesia induced by phase-shifting, (3) to investigate whether the phase-shifting-induced amnesia is due to disturbances of learning, consolidation, and/or retrieval processes, (4) to analyse the specificity of the impaired performance as observed in the passive avoidance procedure, by studying the effect of changing the normal light/dark cycle on extinction of active avoidance behavior, as well as on social and explorative behavior of rats tested in dyadic encounters.

\section{METHOD}

Animals

Male Wistar rats of an inbred strain (CPB-TNO, Zeist, The Netherlands) weighing 130-150 g, were used. The animals housed 5-6 per cage at room temperature $\left(20-21^{\circ} \mathrm{C}\right)$ under ad lib food and water conditions. In the animal colony the lights were on from 6 a.m. to 8 p.m. All observations were made between 8 a.m. and noon, except when otherwise indicated. During experimentation the rats were housed identically, except that the periods that the lights were on and off were changed. The following illumination conditions were used: reversed day/night cycle: lights on from 8 p.m. to 6 a.m., constant light: lights on from 6 a.m. to 6 a.m.; +4 hr phaseshifted: lights on from 10 a.m. to midnight; $-6 \mathrm{hr}$ phaseshifted: lights on from midnight to 2 p.m. These altered illumination schedules remained present during the rest of the experiment.

\section{Behavioral Procedures}

Passive avoidance behavior. Animals were trained in a step-through type one-trial learning passive avoidance test [1]. The experimental apparatus consisted of an illuminated platform attached to a large dark compartment equipped with a grid floor. After habituation to the dark compartment $(2 \mathrm{~min})$ rats were placed on the platform and allowed to enter the dark compartment; since rats prefer dark to light, they normally entered within $15 \mathrm{sec}$. On the next day after three more trials (intertrial interval $5 \mathrm{~min}$ ), unavoidable scrambled footshock $(0.5 \mathrm{~mA}, 2$ or $3 \mathrm{sec})$ was delivered through the grid floor of the dark compartment (learning

\footnotetext{
${ }^{1}$ On leave of absence from Department of Pathophysiology, University Medical School, Szeged, Hungary. Supported in part by Stichting Pharmacologisch Studiefonds, Utrecht, The Netherlands.

${ }^{2}$ Requests for reprints should be addressed to Dr. Jan M. Van Ree, Rudolf Magnus Institute for Pharmacology, Medical Faculty, University of Utrecht, Vondellaan 6, 3521 GD Utrecht, The Netherlands.
} 

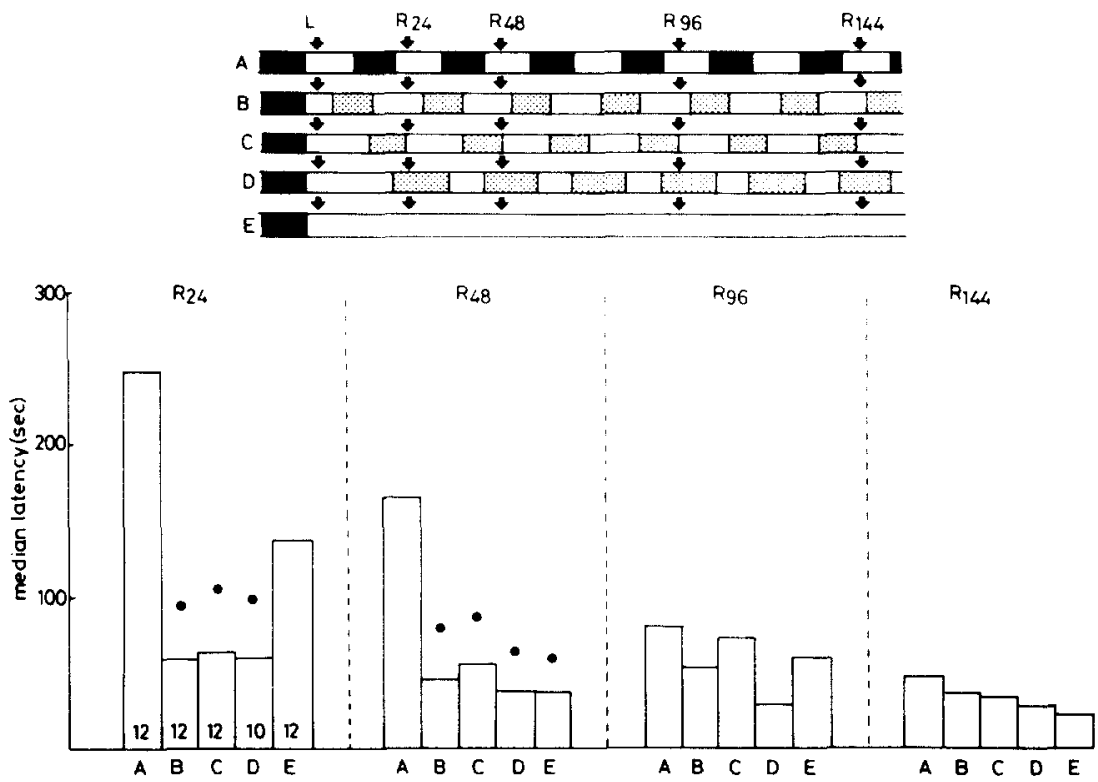

FIG. 1. Effect of different light/dark schedules started after the learning trial ( $L$; footshock parameters: $0.5 \mathrm{~mA}, 2 \mathrm{sec})$ on the $24,48,96$ and 144 hours retention tests $\left(R_{24}, R_{48}, R_{96}\right.$, $R_{144}$, respectively) of passive avoidance behavior. The median avoidance latency is presented in sec. The number of animals per groups is indicated in the columns. A-normal light/dark cycle (lights on from 6 a.m. to 8 p.m.); B-6 hr phase-shifted (lights on from midnight to 2 p.m.); $\mathrm{C}-+4 \mathrm{hr}$ phase-shifted (lights on from 10 a.m. to midnight); D-reversed light/dark cycle (lights on from 8 p.m. to 6 a.m.); E-constant light (lights on from 6 a.m. to 6 a.m.). Open box: lights on; closed box: lights off (normal schedule); dotted box: lights off (altered schedule). - - Different from animals subjected to normal light/dark cycle (A) $(p<0.05$, Mann-Whitney U-test).

trial). Rats were removed from the shock box $10 \mathrm{sec}$ after the termination of the shock. Passive avoidance latencies were tested different times (as mentioned in the Results section) after the learning trial (retention tests); the rats were placed on the platform and the latency to enter the dark compartment was measured up to a $300 \mathrm{sec}$.

Active avoidance behavior " Massed trial" acquisition and extinction). Avoidance conditioning was performed in a shuttle-box as described previously $[2,3]$. The sound of a buzzer served as the conditioned stimulus (CS) for $3 \mathrm{sec}$ prior to the unconditioned stimulus (US) of scrambled electric footshock $(0.21 \mathrm{~mA})$. When the rats had crossed the barrier within $3 \mathrm{sec}$ of the CS presentation the CS was immediately terminated and the response was recorded as a conditioned avoidance response (CAR). If the rats failed to make a response within $20 \mathrm{sec}$ after the onset of CS, both CS and US were terminated. A total of 30 conditioning trials were given in a single session. The average intertrial interval was $60 \mathrm{sec}$, varying between 40 and $80 \mathrm{sec}$. The total number of CARs during the 30 trial session served as the index of avoidance behavior. Extinction session was run on the next day. Thirty non-reinforced trials were presented in a single session, in which the CS was terminated immediately after the rat crossed the barrier within $3 \mathrm{sec}$ (positive response, CAR), or after $3 \mathrm{sec}$ in the absence of a positive response.

Social and explorative behavior. Testing was performed by placing two rats (an experimental rat and a rat exposed to the normal light/dark cycle) together in a perspex observation cage illuminated with red lights for 10 minutes $[7,8]$. The behavior of rats was analysed later from video tapes by individuals who did not know the illumination schedule of the rats. As social explorative behavior was taken the frequency of exploration and anogenital investigation of the test partner; as contact behavior, the frequency of the behavioral acts crawl over, mounting and social grooming and as attentive behavior, the frequency of approaching or following the conspecific. Aggressive-like behavior such as biting, kicking and fighting rarely occurred. In addition, the frequencies of ambulation, rearing wall, rearing field and self-grooming of the individual rats were deterimined. A detailed description of the behaviors is described elsewhere [7].

\section{Statistical Analysis}

The non-parametric ranking tests of Kruskal-Wallis and Mann-Whitney [11] were used for statistical analysis of passive avoidance data. Statistical comparisons of the data concerning social, explorative and active avoidance behavior were performed by analysis of variance and by Student's $t$-test. A probability level of 0.05 or less was accepted as the level of significance.

\section{RESULTS}

Disrupting circadian organisation of animals immediately after the learning trial, caused an attenuation of entrance latencies of passive avoidance behavior (Fig. 1; KruskalWallis tests: $R_{24}: H(4)=12.809, p=0.012 ; R_{4 \mathrm{~s}}: H(4)=11.220$, 

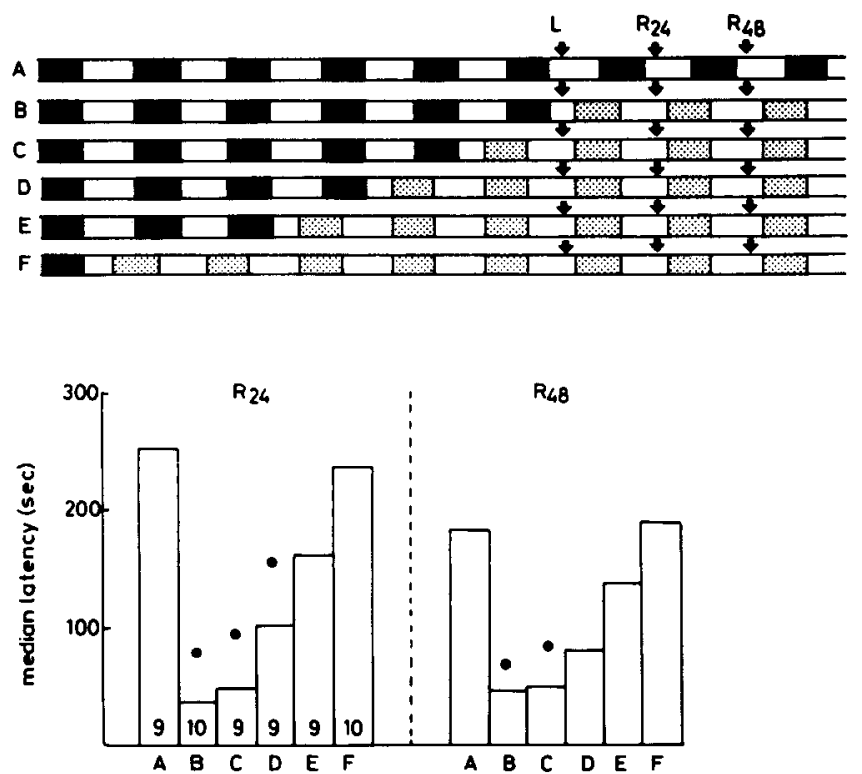

FIG. 2. Effects of $-6 \mathrm{hr}$ phase-shifting (light on from midnight to 2 p.m.) on the 24 hours $\left(R_{24}\right)$ and 48 hours $\left(R_{48}\right)$ retention tests of passive avoidance behavior. Shifting was started immediately after (group B) or 1 (C), 2 (D), 3 (E) or 5 (F) days before the learning trial (L; footshock parameters, $0.5 \mathrm{~mA}, 2 \mathrm{sec}$ ). The median avoidance latency is presented in sec. The number of animals per group is indicated in the columns. Open box: lights on; closed box: lights off (normal schedule); dotted box: lights off (altered schedule). -Different from animals subjected to normal light/dark cycle (A) $(p<0.05$, Mann-Whitney U-test).

$p=0.024 ; \mathrm{R}_{96}: \mathrm{H}(4)=0.791$, N.S.; $\mathrm{R}_{144}=1.316$, N.S.). When the light period on the day of the learning trial was shortened by 6 hours (group B, Fig. 1) or extended by 4 hours (group C), or by 10 hours (reversed day/night cycle; group D) a decreased avoidance latency at 24 and $48 \mathrm{hr}$ retention tests was observed. The same was found when rats were constantly exposed to light (group E), although the effect on the $24 \mathrm{hr}$ retention test did not reach statistical significance. At the $96 \mathrm{hr}$ and $144 \mathrm{hr}$ retention test no differences in performance were present among the various groups.

In the next experiment the time interval between the learning trial and the start of the $-6 \mathrm{hr}$ phase-shifting was consistently varied. The effect of phase-shifting on passive avoidance latency as measured at $24 \mathrm{hr}$ and $48 \mathrm{hr}$ retention tests, gradually diminished, the earlier the phase-shifting started before the learning trial (Fig. 2). Animals shifted immediately after (group B) or one day before (group C) the learning trial showed lower avoidance latencies at the $24 \mathrm{hr}$ and $48 \mathrm{hr}$ retention tests, as compared to that of control animals (group A), while rats shifted two days before the learning trial (group D) showed significantly lower avoidance latencies at the $24 \mathrm{hr}$ retention test. The performance of animals shifted 3 (group E) or 5 days (group F) before the learning trial was not significantly different from that of controls (Kruskal-Wallis tests: $\mathbf{R}_{\mathbf{2 4}}: \mathrm{H}(5)=14.025, p=0.011 ; \mathbf{R}_{\mathbf{4 8}}$ : $\mathrm{H}(5)=9.343, p=0.046)$.

Next, animals were trained and tested during the dark period of day/night cycle. No differences in avoidance latencies were observed among rats tested in the morning
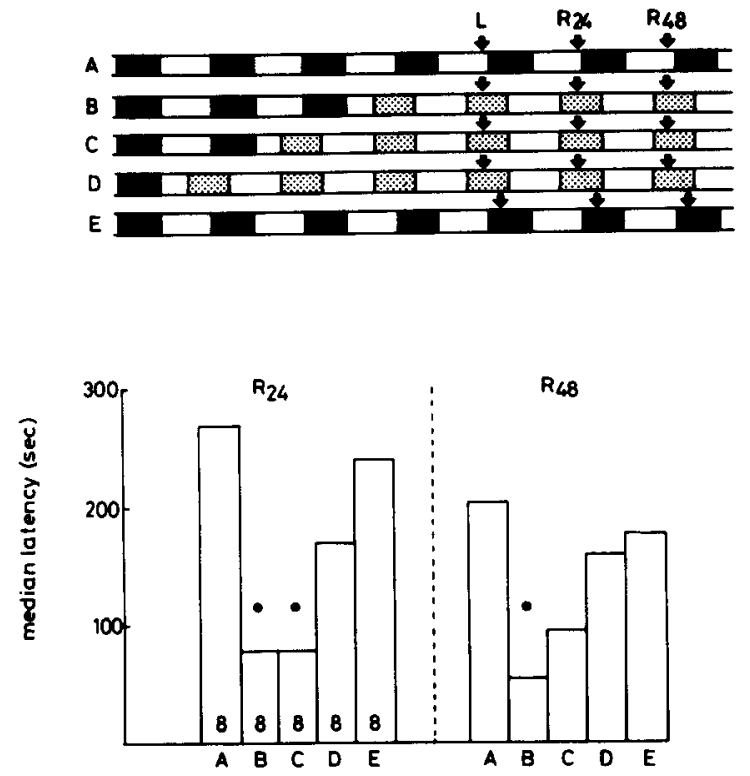

FIG. 3. Effects of $-6 \mathrm{hr}$ phase-shifting (lights on from midnight to 2 p.m.) on the 24 hours $\left(R_{24}\right)$ and 48 hours $\left(R_{48}\right)$ retention tests of the passive avoidance behavior. Phase-shifting started 1 (group B), 2 (C), or 3 (D) days before the learning trial (L; footshock parameters: $0.5 \mathrm{~mA}, 2 \mathrm{sec}$ ), which was performed between $4 \mathrm{p} . \mathrm{m}$. and $6 \mathrm{p} . \mathrm{m}$. In one group of animals (group E), subjected to the normal day/night cycle, teaching and retention took place between $10 \mathrm{p} . \mathrm{m}$. and midnight. The median avoidance latency is presented in sec. The number of animals per group is indicated in the columns. Open box: lights on; closed box: lights off (normal schedule); dotted box: lights off (altered schedule). -Different from animals subjected to normal light/dark cycle (A) $(p<0.05$, Mann-Whitney U-test).

(group A, Figs. 1 and 2) or at the end of the afternoon (group A, Fig. 3) during the light phase, or at the end of the evening (group E, Fig. 3) during the dark phase of the normal cycle. Animals $-6 \mathrm{hr}$ shifted one day before the learning trial (group B, Fig. 3), and tested during the dark phase of the shifted cycle showed lower avoidance latencies at the 24 and 48 hours retention tests as compared to the control animals (group $\mathrm{A}$ and $\mathrm{E}$ ), while in rats shifted two days before the learning trial (group C) the avoidance latency was significantly attenuated at the $24 \mathrm{hr}$ retention test. When the phase-shifting started three days before the learning trial (group D), no effect of phase-shifting was found (KruskalWallis test: $\mathbf{R}_{24}: H(4)=9.819, p=0.045 ; \mathbf{R}_{48}: H(4)=9.695$, $p=0.047$ ).

To analyse whether phase-shifting influences consolidation or retrieval processes, animals in which the first retention test was postponed till 6 days after the learning trial, were $-6 \mathrm{hr}$ phase-shifted immediately or 5 days after the learning trial, thus 6 days or 1 day respectively before the retention trial. Two experiments were performed in which the duration of the footshock was 2 or $3 \mathrm{sec}$ (Fig. 4). The higher footshock resulted in a somewhat, but not statistically significant higher avoidance latency at the 144 and 168 hours retention tests (groups A and D, Fig. 4). When phase-shifting started 5 days after the learning trial, thus 1 day before the first retention test, attenuated latencies were found as compared to those of control animals. The performance of rats in which phase-shifting started immediately after the learning, thus 6 days before the first retention test, appeared to be 

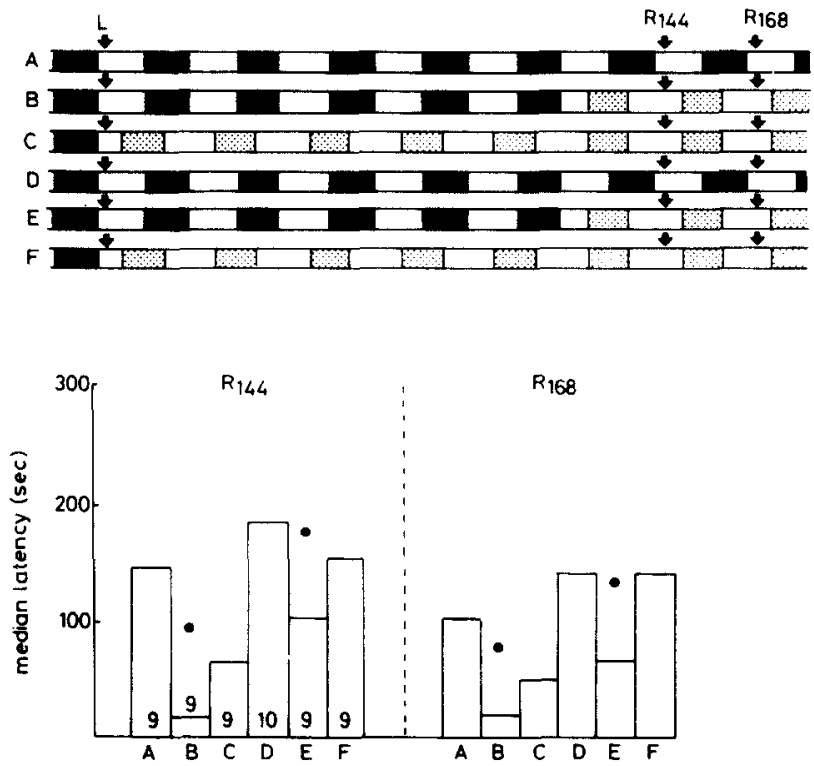

FIG. 4. Effects of $-6 \mathrm{hr}$ phase-shifting (lights on from midnight to 2 p.m.) on the 144 hours $\left(R_{144}\right)$ and 168 hours $\left(R_{16 k}\right)$ retention tests of passive avoidance behavior. Phase-shifting started 5 days (groups $B$ and $\mathrm{E}$ ) or immediately (groups $\mathrm{C}$ and $\mathrm{F}$ ) after the learning trial ( $\mathrm{L}$; footshock parameters: $0.5 \mathrm{~mA}, 2 \mathrm{sec}$ (groups A, B and C); $0.5 \mathrm{~mA}, 3$ $\sec$ (groups $\mathrm{D}, \mathrm{E}$ and $\mathrm{F}$ )). The median avoidance latency is presented in sec. The number of animals per group is indicated in the columns. Open box: lights on; closed box: lights off (normal schedule); dotted box: lights off (altered schedule). - Different from animals subjected to normal light/dark cycle (groups A or D, respectively).
TABLE 1

EFFECTS OF -6 HR PHASE-SHIFTING (LIGHTS ON FROM MIDNIGHT TO 2 P.M.) ON THE EXTINCTION OF SHUTTLE-BOX ACTIVE AVOIDANCE BEHAVIOR

\begin{tabular}{llll}
\hline & $\mathrm{N}$ & Acquisition & Extinction \\
\hline Control & 10 & $16.2 \pm 0.8^{*}$ & $14.4 \pm 0.9$ \\
Phase-shifted & 10 & $15.2 \pm 1.1$ & $9.2 \pm 1.1^{\dagger}$
\end{tabular}

Rats were shifted immediately after the "massed-trial" acquisition; the next day their extinction was tested.

*Mean \pm SEM of total number of conditioned avoidance responses.

$\dagger p<0.01$ as compared to controls (Student $t$-test: $t(19)=3.784$ ).

$\mathrm{N}=$ number of animals.

TABLE 2

EFFECTS OF REVERSED DAY/NIGHT CYCLE OR EXPOSURE TO CONSTANT LIGHT ON SOCIAL AND EXPLORATIVE BEHAVIORS OF RATS, TESTED IN DYADIC ENCOUNTERS FOR $10 \mathrm{MIN}$

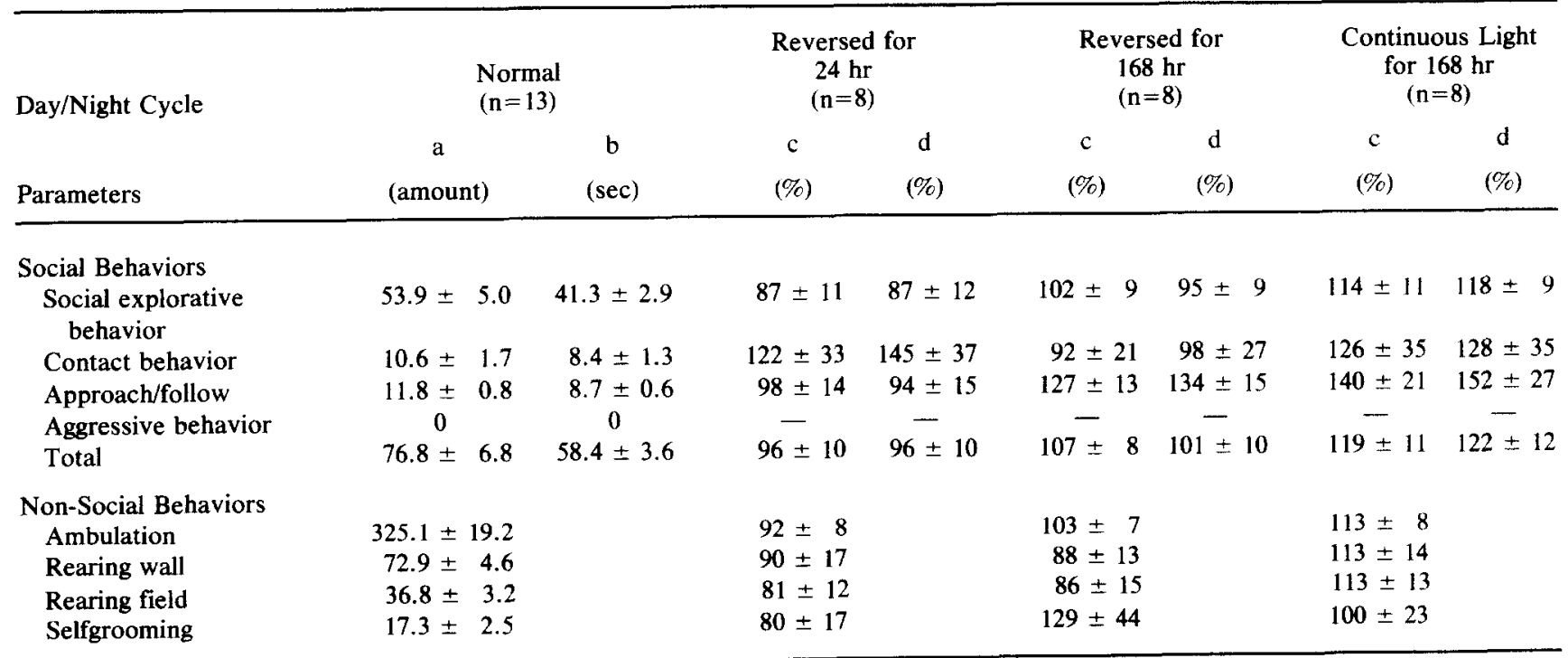

The day/night cycles (normal cycle: lights on from $6 \mathrm{a} . \mathrm{m}$. to $8 \mathrm{p} . \mathrm{m}$.) were changed $24 \mathrm{hr}$ (reversed cycle: lights on from $8 \mathrm{p} . \mathrm{m}$. to $6 \mathrm{a} . \mathrm{m}$.) or $168 \mathrm{hr}$ (reversed cycle or continuous light) before testing. Rats subjected to a normal day/night cycle (normal) or to a reversed cycle or continuously light were tested with a rat exposed to a normal light/dark cycle (test-partner). ANOVA-testing revealed no differences in behaviors between the rats subjected to various day/night schedules, neither in behaviors between the test partners of these rats.

a,c: Mean \pm SEM frequency of absolute values (a) or percentage of controls (c).

$b, d$ : Mean \pm SEM duration in sec (b) or in percentage of controls (d).

$\mathrm{n}$ : Number of animals. 
somewhat lower than that of controls, but this effect did not reach statistical significance.

Immediately after acquisition of shuttle-box active avoidance behavior, rats were subjected to $-6 \mathrm{hr}$ phaseshifting (light on from midnight to 2 p.m.). It appeared the next day that phase-shifting resulted in a facilitated extinction as compared to rats subjected to the normal day/night cycle (Table 1). The various social interactions and explorative behavior of rats tested in dyadic encounters were not affected by exposure to a reversed day/night cycle for 1 or 7 days, or by continuous exposure to light for 7 days (Table 2).

\section{DISCUSSION}

The present data show that disrupting circadian organization in rats by a phase-shift (either +4 hours or -6 hours) or a reversed day/night schedule or by continuous exposure to light immediately after the learning trial produces a retrograde amnesia. This amnesia was present for at least 2 days when the rats were repeatedly tested for passive avoidance performance. The recovery of impaired performance after some days is likely due to adaptation of the rats to the new illumination schedule. Tapp and Holloway [9] showed that the retrograde amnesia lasted longer, when rats were tested only once. To analyse the duration of the deficit in more detail, rats were phase-shifted, starting at different days before the learning trial. It appeared that the retention deficit gradually diminished the longer the rats were exposed to the new illumination cycle. Thus, the impaired retention performance is not present when rats have already been exposed to phase-shifting for 3-5 days before the learning trial, suggesting that with respect to memory processes the rats adapt to the new illumination cycle in about 3 days. The amnesia due to disrupting circadian organization may result from disturbances of learning, consolidation or retrieval processes. Learning of passive avoidance takes place during and immediately after the acquisition trial, experiences during the acquisition trial are consolidated in the first hours after the acquisition trial, while the stored information is retrieved during the retention trial. Thus, treatments shortly after the acquisition trial may primarily affect learning and especially consolidation processes, while those shortly before the retention trial may influence retrieval processes [6]. Rats in which phase-shifting was actually started approximately 4 and 10 hours after the learning trial, showed retrograde amnesia at the $24 \mathrm{hr}$ retention test, suggesting that retrieval processes rather than learning or consolidation processes are disrupted by changing the circadian rhythm. Consistently, rats exposed to the learning trial 6 days before the retention test and shifted 24 hours before testing for retention, displayed impaired performance. The deficit in retention due to phase-shifting does not depend on time of the day that tests took place, since rats tested in the dark phase displayed an impairment in performance comparable to rats tested in the light phase. Extinction of active avoidance behavior appeared to be facilitated in phase-shifted rats as compared to controls, indicating that the amnesia induced by phase-shifting is not restricted to passive avoidance behavior. Previous studies have shown that changes in the environment before (isolation for 4-7 days) or during (intense light) testing markedly affect the level of social behaviors of rats tested in dyadic encounters $[7,8]$. However, neither reversal of the illumination cycle nor continuous exposure to light changed the various aspects of social interactions and explorative behavior. These data indicate that the retention deficit as found in active and passive avoidance behavior is not related to (aspecific) effects on motor activity of the rats and suggest that phase-shifting makes the rats amnestic for recently acquired, newly learned behavioral responses, but not for more innate behavioral patterns. Performance deficits of rats induced by phase-shifting the normal day/night cycle may be comparable to disturbances in travellers suffering from jet lag. Thus, the present data suggest that jet lag may result in amnesia for recently acquired information.

\section{REFERENCES}

1. Ader, R., A. W. M. Weijnen and P. Moleman. Retention of a passive avoidance response as a function of the intensity and duration of electric shock. Psychon Sci 26: 125-128, 1972.

2. Bohus, B. and D. De Wied. Actions of ACTH- and MSH-like peptides on learning, performance, and retention. In: Endogenous Peptides and Learning and Memory Processes, edited by J. L. Martinez, Jr., R. A. Jensen, R. B. Messing, H. Rigter and J. L. McGaugh. New York: Academic Press, 1981, pp. 397-411.

3. Fekete, M., B. Bohus and D. De Wied. Comparative effects of ACTH-related peptides on acquisition of shuttle-box avoidance behavior of hypophysectomized rats. Neuroendocrinology 36: $112,-118,1983$.

4. Holloway, F. A. and R. A. Wansley. Multiple retention deficits at periodic intervals after passive avoidance learning. Science 180: 208-210, 1973.

5. Holloway, F. A. and R. A. Wansley. Multiple retention deficits after active and passive avoidance learning. Behav Biol 9: 1-14, 1973.
6. McGaugh, J. L. Time-dependent processes in memory storage. Science 153: 1351-1358, 1966.

7. Niesink, R. J. M. and J. M. Van Ree. Short-term isolation increases social interactions of male rats: A parametric analysis. Physiol Behav 29: 819-825, 1982.

8. Niesink, R. J. M. and J.M. Van Ree. Normalizing effect an adrenocorticotropic hormone (4-9) analog ORG 2766 on disturbed social behavior in rats. Science 221: 960-962, 1983.

9. Tapp, W. N. and F. A. Holloway. Phase shifting circadian rhythms produces retrograde amnesia. Science 211: 1056-1058, 1981.

10. Wansley, R. A. and F. A. Holloway. Multiple retention deficits following one-trial appetitive training. Behav Biol 14: 135-149, 1975.

11. Weber, E. Nonparametric methods. In: Biostatistics in Pharmacology, vol 2, edited by A. L. Delaunois. New York: Pergamon Press, 1979, pp. 889-970. 